\title{
Effect of conventional and non-inversion tillage systems on the abundance and some life history traits of carabid beetles (Coleoptera: Carabidae) in winter triticale fields
}

\author{
Agnieszka KOSEWSKA ${ }^{1}$, Tomasz SKALSKI ${ }^{2}$ and Mariusz NIETUPSKI ${ }^{1}$ \\ ${ }^{1}$ Department of Phytopatology and Entomology, University of Warmia and Mazury, Prawocheńskiego 17, 10-719 Olsztyn, Poland; \\ e-mails: a.kosewska@uwm.edu.pl; mariusz.nietupski@uwm.edu.pl \\ ${ }^{2}$ Department of Entomology, Institute of Zoology, Jagiellonian University, Gronostajowa 9, 30-387 Kraków, Poland; \\ e-mail: tomasz.skalski@uj.edu.pl
}

Key words. Coleoptera, Carabidae, ground beetles, life traits, plough, non-inversion tillage, triticale

\begin{abstract}
Soil cultivation is among the principal factors that determine the structure and properties of soil and also affects the species composition and abundance of soil dwelling arthropods. Carabid beetles are a particularly valuable group of arthropods, the species of which are strongly associated with particular soil environments. This paper discusses the effect of soil tillage on carabid beetle assemblages. The study was carried out near Olsztyn, in northeastern Poland. Six wheat fields, each cultivated using either, conventional or non-inversion, soil tillage, were chosen. Carabid beetles were caught in Barber's traps from early April to the end of October 2011. In total, 7,486 specimens belonging to 55 species of the family Carabidae were captured. The most numerous were Poecilus cupreus, Pterostichus melanarius, Harpalus rufipes, Anchomenus dorsalis and Carabus granulatus. Differences in the abundance of ground beetles and some life history traits were associated with the two soil tillage systems. In particular, ploughing reduced carabid abundance and resulted in the increased activity of medium-sized zoophages and spring breeders.
\end{abstract}

\section{INTRODUCTION}

Arable fields are ecosystems in which the ecological relationships are largely dependent on human intervention. Among the typical inhabitants of agricultural landscapes are carabid beetles (Thiele, 1977; Holland \& Luff, 2000; Aleksandrowicz et al., 2008; Wamser et al., 2012). In terms of their abundance, species composition and life history parameters they are highly sensitive to changes in microenvironments and disturbances caused by human activities. Because of this carabid beetles are often used as bioindicators of habitats (Rainio \& Niemelä, 2003; Koivula, 2011; Schwerk \& Szyszko, 2011; Skalski et al., 2011), including those subjected to agricultural practices (Kromp, 1999; Irmler, 2003; Holland, 2004; Twardowski, 2010; Skłodowski, 2013). Carabids are a particularly important group of animals in arable fields. These beetles, which are mostly predators, contribute to the biological control of pests (Hengeveld, 1980; Lövei \& Sunderland, 1996; Sunderland, 2002; Hurej \& Twardowski, 2006; Saska, 2007). Because of their abundance in in fields they are a significant component of the environment's natural resistance, which helps prevent outbreaks of crop pests. Epigeic carabid beetles as top predators affect the cycles of matter and are an important part of the food web. Soil is one of the most important elements affecting the survival of soil dwelling organisms (Thiele, 1977; Huruk, 2002; Nietupski et al., 2010). Species composition, abundance and life history traits of carabids depend on several factors, including soil treatment (Andersen, 1999, 2003; Holland \& Reynolds, 2003; Sądej et al., 2012; Skłodowski, 2014). Current tillage systems can be divided into two main categories: conventional tillage with ploughing and conservation tillage, known more widely as non-inversion tillage (Morris et al., 2010). Conventional tillage by reversing the furrows by ploughing can detrimentally affect soil fauna. Damage of soil organisms by ploughing causes their death and destroys the associations between soil organisms, which adversely affect the condition of the soil (Arshad, 1999; Kromp, 1999; Holland \& Luff, 2000; Marasas et al., 2001). Conservation tillage is predominantly ploughless cultivation and typically does not displace soil-dwelling organisms. Therefore, carabid beetles and other soil-organisms potentially have a greater chance of survival.

Understanding what determines the stability of carabid communities in agricultural ecosystems is one of the principal aims of integrated plant protection programs, which at the current stage of development of farming (integrated agricultural production (IPM) started in Poland in 2014) and nature conservation is an essential requirement.

The purpose of this study was to determine the species composition of ground beetles colonizing fields of winter triticale cultivated using two different systems of soil tillage - conventional and non-inversion. Another objective was to try and account for the changes in life history traits of ground beetles in particular soil tillage systems.

The following hypotheses were tested: (1) Ploughing causes a decrease in abundance and species diversity of carabid beetles. (2) When compared to conventional tillage systems carabids in non-inversion tillage systems characteristically differ in their life history traits, e.g., there are more large zoophagous and fewer hemizoophagous and 
TABLE 1. Species composition and abundance of the different species of Carabidae caught in the two types of fields studied.

\begin{tabular}{|c|c|c|c|c|c|c|}
\hline \multirow{3}{*}{ Species / Ecological characteristics } & \multicolumn{6}{|c|}{ Type of culltivation } \\
\hline & \multicolumn{3}{|c|}{ Non-inversion (fields) } & \multicolumn{3}{|c|}{ Conventional (fields) } \\
\hline & 1 & 2 & 3 & 4 & 5 & 6 \\
\hline Amara aenea $($ Degeer,1774) / Ph/S & 0 & 0 & 0 & 0 & 1 & 1 \\
\hline Amara communis (Panzer,1797) / Hz/S & 0 & 0 & 1 & 1 & 0 & 1 \\
\hline Amara consularis (Duftschmid,1812) / Hz/A & 0 & 0 & 1 & 0 & 0 & 0 \\
\hline Amara convexior Stephens, 1828 / Hz/S & 1 & 2 & 2 & 1 & 0 & 0 \\
\hline Amara ovata (Fabricius, 1792) / Hz/S & 9 & 3 & 1 & 1 & 2 & 0 \\
\hline Amara plebeja (Gyllenhal,1810) / $\mathrm{Ph} / \mathrm{S}$ & 5 & 0 & 2 & 3 & 6 & 2 \\
\hline Amara similata (Gyllenhal,1810)/ Ph/S & 6 & 7 & 3 & 0 & 1 & 3 \\
\hline Amara spreta Dejean, 1831 / Hz/S & 0 & 0 & 0 & 1 & 0 & 1 \\
\hline Anchomenus dorsalis (Pontoppidan,1763) / Mz/S & 179 & 178 & 208 & 55 & 67 & 70 \\
\hline Anisodactylus binotatus (Fabricius, 1787) / Hz/S & 1 & 1 & 7 & 2 & 0 & 1 \\
\hline Asaphidion flavipes (Linnaeus, 1761) / Sz/S & 4 & 3 & 3 & 3 & 0 & 1 \\
\hline Bembidion guttula (Fabricius, 1792) / Sz/S & 4 & 2 & 1 & 3 & 2 & 4 \\
\hline Bembidion lampros (Herbst, 1784) / Sz/S & 6 & 4 & 8 & 6 & 4 & 2 \\
\hline Bembidion properans (Stephens,1828) / Sz/S & 1 & 2 & 0 & 3 & 3 & 2 \\
\hline Bembidion quadrimaculatum (Linnaeus, 1761) / Sz/S & 7 & 3 & 4 & 0 & 0 & 0 \\
\hline Broscus cephalotes (Linnaeus, 1758) / Lz/A & 3 & 0 & 0 & 0 & 0 & 0 \\
\hline Calathus ambiguus (Paykull,1790) / Mz/A & 0 & 5 & 0 & 11 & 6 & 6 \\
\hline Calathus cinctus Motschulsky, 1850 / Mz/A & 1 & 1 & 2 & 12 & 4 & 0 \\
\hline Calathus erratus (Sahlberg,1827) / Mz/A & 0 & 0 & 0 & 2 & 1 & 0 \\
\hline Calathus fuscipes (Goeze,1777) / Mz/A & 15 & 17 & 12 & 41 & 41 & 40 \\
\hline Calathus halensis (Schaller,1783) / Lz/A & 0 & 0 & 0 & 1 & 0 & 0 \\
\hline Calathus melanocephalus (Linnaeus,1758) / Mz/A & 2 & 1 & 2 & 2 & 1 & 0 \\
\hline Carabus cancellatus Illiger, 1798 / Lz/S & 2 & 6 & 1 & 0 & 1 & 4 \\
\hline Carabus granulatus Linnaeus, 1758 / Lz/S & 143 & 226 & 120 & 95 & 90 & 64 \\
\hline Carabus nemoralis O.F.Muller, 1764 / Lz/S & 1 & 0 & 0 & 0 & 1 & 0 \\
\hline Chlaenius nigricornis (Fabricius, 1787) / Mz/S & 0 & 0 & 0 & 0 & 1 & 0 \\
\hline Clivina fossor (Linnaeus, 1758 ) / Mz/S & 1 & 0 & 0 & 1 & 0 & 0 \\
\hline Curtonotus aulicus (Panzer, 1797) / Hz/A & 0 & 1 & 0 & 0 & 0 & 0 \\
\hline Harpalus affinis (Schrank,1781) / Hz/S & 32 & 33 & 35 & 2 & 4 & 5 \\
\hline Harpalus griseus (Duftschmid,1812) / Hz/A & 1 & 1 & 0 & 1 & 0 & 0 \\
\hline Harpalus latus (Linnaeus, 1758) / Hz/A & 0 & 0 & 2 & 1 & 0 & 0 \\
\hline Harpalus luteicornis (Duftschmid,1812) / Hz/S & 3 & 2 & 3 & 3 & 1 & 6 \\
\hline Harpalus progrediens Schauberger,1922 / Hz/S & 0 & 0 & 1 & 0 & 0 & 0 \\
\hline Harpalus rubripes (Duftschmid,1812) / Hz/S & 0 & 0 & 1 & 1 & 0 & 0 \\
\hline Harpalus rufipes (Degeer,1774) / Hz/A & 143 & 176 & 126 & 89 & 84 & 82 \\
\hline Harpalus signaticornis (Duftschmid,1812) / Hz/S & 0 & 0 & 0 & 0 & 2 & 0 \\
\hline Harpalus smaragdinus (Duftschmid,1812) / Hz/S & 0 & 0 & 1 & 0 & 0 & 0 \\
\hline Harpalus tardus (Panzer,1797) / Hz/S & 0 & 1 & 3 & 1 & 1 & 2 \\
\hline Limodromus assimilis (Paykull,1790) / Mz/S & 4 & 3 & 4 & 2 & 5 & 5 \\
\hline Loricera pilicornis (Fabricius, 1775) / Mz/S & 2 & 2 & 3 & 12 & 5 & 8 \\
\hline Nebria brevicollis (Fabricius, 1792) / Lz/A & 2 & 7 & 9 & 5 & 10 & 4 \\
\hline Notiophilus palustris (Duftschmid,1812)/ Sz/S & 3 & 2 & 6 & 12 & 6 & 7 \\
\hline Poecilus cupreus (Linnaeus, 1758 ) / Mz/S & 1132 & 479 & 565 & 498 & 538 & 403 \\
\hline Poecilus lepidus (Leske,1785) / Mz/S & 1 & 0 & 0 & 0 & 0 & 1 \\
\hline Poecilus versicolor (Sturm,1824) / Mz/S & 21 & 19 & 19 & 15 & 17 & 4 \\
\hline Pterostichus anthracinus (Illiger,1798) / Mz/S & 0 & 0 & 0 & 0 & 1 & 0 \\
\hline Pterostichus diligens (Sturm,1824) / Sz/S & 1 & 0 & 0 & 0 & 0 & 0 \\
\hline Pterostichus melanarius (Illiger,1798) / Lz/A & 76 & 128 & 114 & 147 & 170 & 132 \\
\hline Pterostichus niger (Schaller,1783) / Lz/A & 0 & 3 & 0 & 7 & 14 & 11 \\
\hline Pterostichus nigrita (Paykull,1790) / Mz/S & 0 & 0 & 0 & 0 & 1 & 0 \\
\hline Pterostichus strenuus (Panzer,1797) / Sz/S & 0 & 0 & 1 & 0 & 0 & 0 \\
\hline Pterostichus vernalis (Panzer,1796) / Sz/S & 1 & 2 & 2 & 0 & 1 & 0 \\
\hline Stomis pumicatus (Panzer,1796) / Mz/A & 1 & 0 & 0 & 0 & 3 & 1 \\
\hline Synuchus vivalis (Illiger,1798) / Mz/A & 0 & 0 & 0 & 1 & 0 & 0 \\
\hline Trechus quadristriatus (Schrank,1781) / Sz/A & 4 & 10 & 9 & 26 & 10 & 11 \\
\hline \multirow{2}{*}{ Total individuals } & 1818 & 1330 & 1282 & 1067 & 1105 & 884 \\
\hline & \multicolumn{3}{|c|}{4430} & \multicolumn{3}{|c|}{3056} \\
\hline \multirow{2}{*}{ Total species } & 35 & 32 & 35 & 36 & 35 & 30 \\
\hline & & 46 & & & 47 & \\
\hline
\end{tabular}

$\mathrm{Ph}$ - phytophage, $\mathrm{Hz}$ - hemizoophage, $\mathrm{Sz}$ - small-zoophage, $\mathrm{Mz}$ - medium-zoophage, Lz - large-zoophage, $\mathrm{A}$ - autumn breeder, $\mathrm{S}$ spring breeder. 
TABLE 2. GLM of the effect of type of soil cultivation and period when sampled on abundance and species richness of ground beetle assemblages.

\begin{tabular}{lccc}
\hline \multicolumn{1}{c}{ Abundance } & df & Wald Stat. & $\mathrm{p}$ \\
\hline Date & 12 & 3653.45 & 0.000 \\
Treatment & 1 & 8.44 & 0.004 \\
Date*Treatment & 11 & 746.12 & 0.000 \\
\hline \multicolumn{1}{c}{ Richness } & $\mathrm{df}$ & Wald Stat. & $\mathrm{p}$ \\
\hline Date & 12 & 415.65 & 0.000 \\
Treatment & 1 & 0.33 & 0.564 \\
Date*Treatment & 11 & 39.71 & 0.000
\end{tabular}

small zoophagous species, and more autumn-active than spring-active carabid beetles.

\section{MATERIAL AND METHODS}

The experiment was conducted in fields near Olsztyn, in northeastern Poland (UTM DE 65). Six of the fields were planted with winter triticale, three of which were subjected to conventional soil tillage, for which furrow slice turning ploughs were used, followed by a tiller harrow to prepare the soil for sowing. Another three fields were subjected to reduced tillage, namely noninversion tillage, where the soil was cultivated with a special soil mixing aggregate without turning furrows or slicing. The soil in all the fields was similar and and ranked as a good wheat complex soil (class IIIa and IIIb). Modified Barber traps (plastic cups $10 \mathrm{~cm}$ diameter, $15 \mathrm{~cm}$ deep with ethylene glycol) were used to catch insects. Six traps were placed in each field, at a distance of 20 meters from one another. The traps were emptied every two weeks. Ground beetles were caught from early April to the end of October 2011. The traps were removed during harvest and when the soil was tilled for sowing (1 month).

The species composition and abundance of the carabids were determined. The beetles were divided into groups based on the following criteria: feeding strategy and type of breeding. Trophic groups were: phytophages (feeding only on plants), hemizoophages (otherwise called omnivores, feeding on a broad spectrum of food consisting of both plants and animals), small zoophages (body length less than $5 \mathrm{~mm}$ ), medium zoophages $(5.1-12 \mathrm{~mm}$ ) and large zoophages (body length more than $12 \mathrm{~mm}$ ). The group of typical phytophagous animals was extremely small, which is why it was excluded from further analyses. In addition the carabids were classified as either autumn breeders, which reproduce in autumn and hibernate as larvae, or spring breeders, which hibernate as adults and reproduce in spring (Larsson, 1939). These aspects of carabid life histories are considered to be the best for describing carabid groups in field crops. Food preferences are an indicator of the availability and variety of food present. The presence of predators of different sizes is also evidence of a rich a food base and occurrence of disturbances when one size class of carabid outlasts another. Occurrence of carabids in various stages of development is also a reflection of the prevailing field conditions.

The differences in mean species richness and abundance of whole assemblages and number of life-history traits recorded in the two treatments and the thirteen sampling periods were tested using a Poisson generalized linear model (GLM), which included two quantitative factors (soil cultivation system and sampling period). Tests for the significance of the effects in the model were done using the Wald statistic.

Indirect ordination of the carabid beetle assemblages recorded was done using non-metric multidimensional scaling (NMDS). NMDS was calculated in WinKyst 1.0 (Šmilauer, 2002) on a

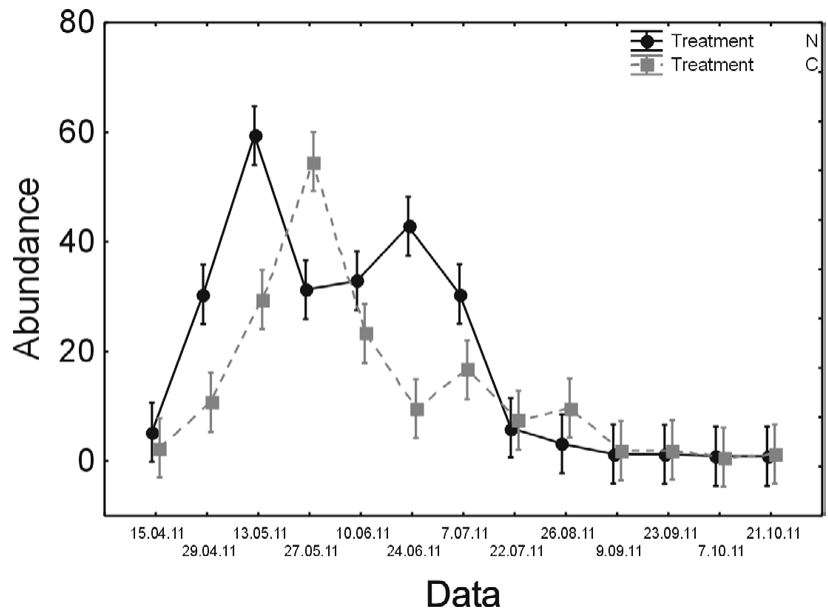

Fig. 1. Average abundance of the carabids recorded during the course of a year in wheat fields in which the soil was cultivated in one of two different ways: $\mathrm{N}$ - non-inversion, $\mathrm{C}$ - conventional. (The vertical lines indicate 0.95 confidence interval.)

Bray-Curtis similarity matrix, based on an initial configuration generated by principal coordinate analysis. The plot was oriented using Principal Component Analysis (PCA) with untransformed data. The significance of the multivariance differences among carabid assemblages was tested using non-parametric analyses of variance PERMANOVA (NPMANOVA) tests with 9,999 permutations. PERMANOVA is a non-parametric permutational test for significant differences between two or more groups, based on any distance measure (Anderson, 2001).

\section{RESULTS}

In total, 7,486 specimens belonging to 55 species of the family Carabidae were captured in the study fields (Table 1). The most numerous species living in the winter triticale fields were Poecilus cupreus, Pterostichus melanarius, Harpalus rufipes, Anchomenus dorsalis and Carabus granulatus. Ground beetle abundance and richness were significantly associated with arable field treatment and season (Table 2). There was a significant difference in seasonal abundance recorded in the two soil tillage systems (Fig. 1).

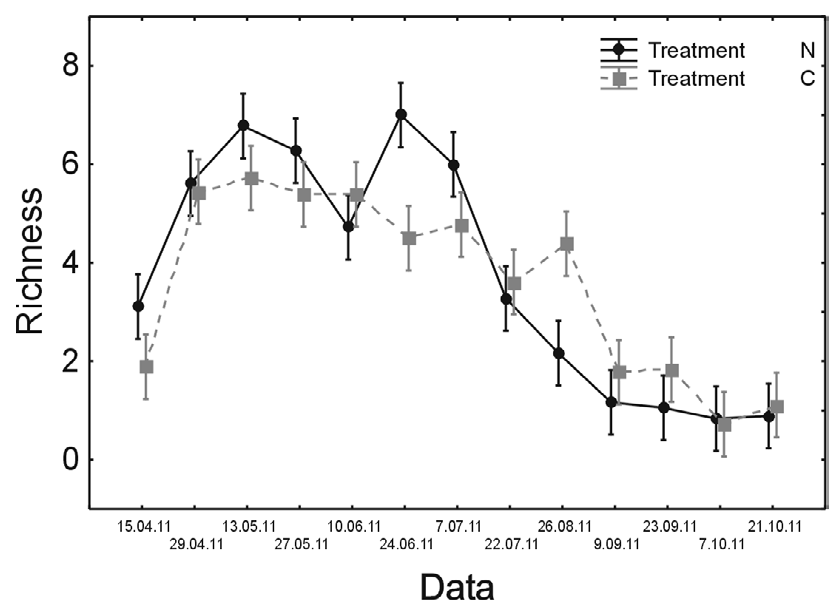

Fig. 2. Average species richness of the carabids recorded during the course of a year in wheat fields in which the soil was cultivated in one of two different ways: $\mathrm{N}$ - non-inversion, $\mathrm{C}$ - conventional. (The vertical lines indicate 0.95 confidence interval.) 


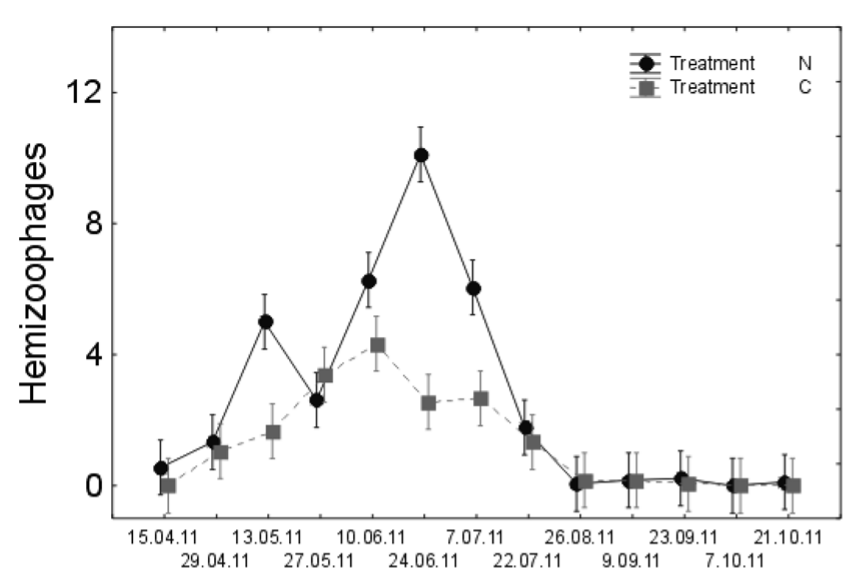

Date

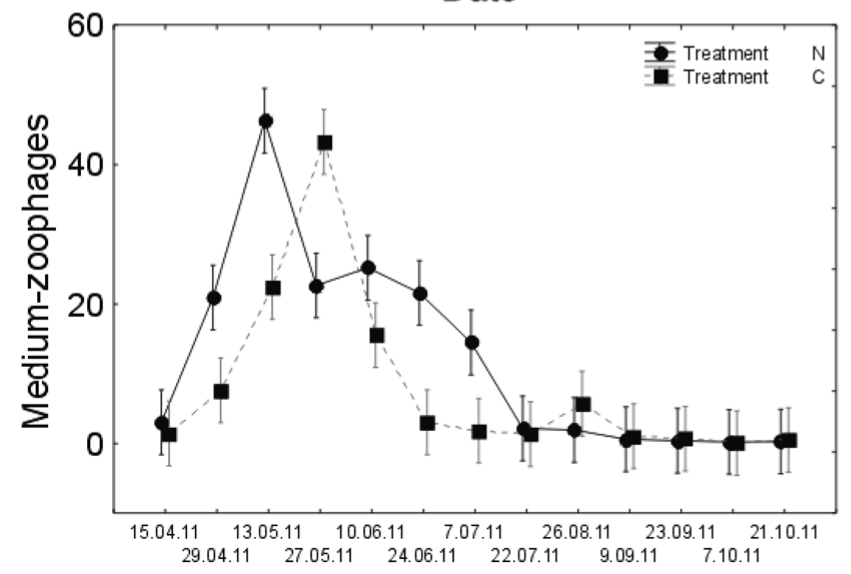

Date

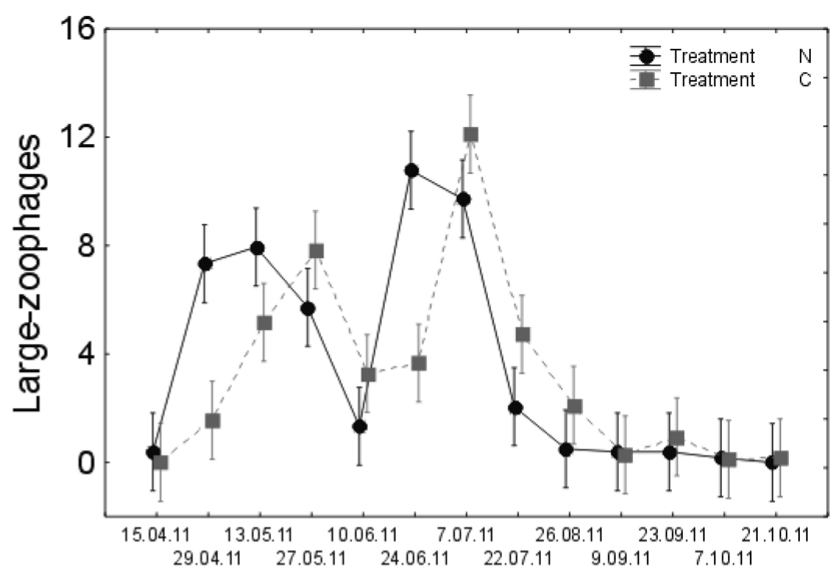

Date

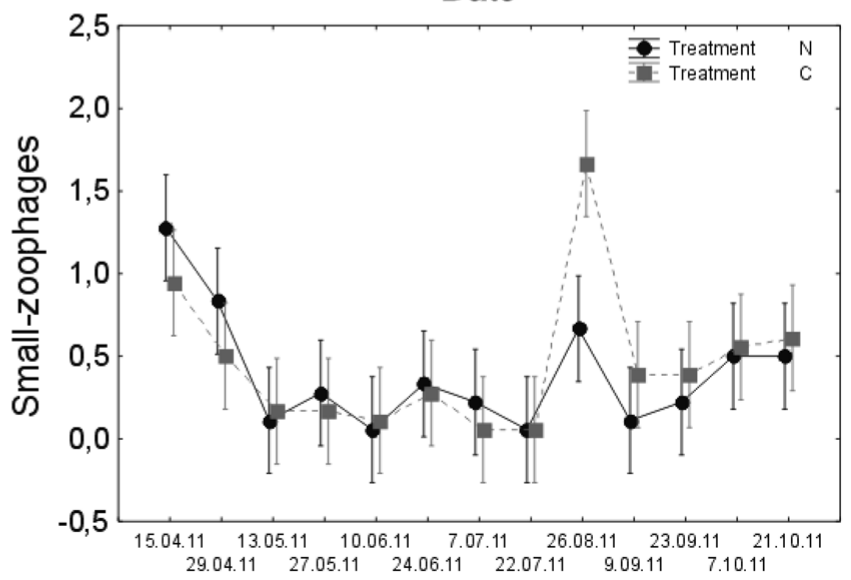

Date

Fig. 3. Average abundance of carabids belonging to different ecological groups recorded during the course of a year in wheat fields in which the soil was cultivated in one of two different ways: $\mathrm{N}$ - non-inversion, $\mathrm{C}$ - conventional. (The vertical lines indicate 0.95 confidence interval.)

The peak abundance occurred earlier and lasted until midJuly at non-inverted sites, whereas in conventional fields the peak in abundance was recorded at the end of May after

TABLE 3. Results of the GLM test of significance (Wald statistics) of the effect of type of soil cultivation and period when sampled on body size and food preferences of ground beetle assemblages.

\begin{tabular}{lccc}
\hline \multicolumn{1}{c}{ Hemizoophages } & df & Wald Stat & $\mathrm{p}$ \\
Date & 12 & 1649.23 & 0.000 \\
Treatment & 1 & 11.58 & 0.001 \\
Date*Treatment & 11 & 59.50 & 0.000 \\
\hline \multicolumn{1}{c}{ Small-zoophages } & & & \\
Date & 12 & 53.72 & 0.000 \\
Treatment & 1 & 0.17 & 0.683 \\
Date*Treatment & 11 & 27.69 & 0.047 \\
\hline$\quad$ Medium-zoophages & & & \\
Date & 12 & 35807.03 & 0.000 \\
Treatment & 1 & 288.42 & 0.000 \\
Date*Treatment & 11 & 1142.24 & 0.000 \\
\hline$\quad$ Large-zoophages & & & \\
Date & 12 & 4864.55 & 0.000 \\
Treatment & 1 & 0.00 & 0.995 \\
Date*Treatment & 11 & 236.81 & 0.000 \\
\hline
\end{tabular}

which numbers declined and oscillated near the minimum for almost half the season. There were slightly differences in the seasonal distribution of species in the two treatments (Fig. 2). In both treatments, the average species richness was highest early in the season and declined at the end of summer. With respect to this parameter only, soil tillage was not a significant factor, but gained significance when season was included (Table 2).

Analysis of the selected life history traits of food preference and body size of the carabids revealed statistically significant differences in terms of the seasonal presence of the aforementioned groups of carabids associated with

TABLE 4. GLM test of significance (Wald statistics) of the effect of type of soil cultivation and period when sampled on when in a year the various species in the ground beetle assemblages breed.

\begin{tabular}{lccc}
\hline \multicolumn{1}{c}{ Spring breeders } & $\mathrm{df}$ & Wald Stat & $\mathrm{p}$ \\
Date & 12 & 45340.51 & 0.000 \\
Treatment & 1 & 132.21 & 0.000 \\
Date*Treatment & 11 & 1329.51 & 0.000 \\
\hline \multicolumn{1}{c}{ Autumn breeders } & & & \\
Date & 12 & 6191.45 & 0.000 \\
Treatment & 1 & 44.75 & 0.000 \\
Date*Treatment & 11 & 282.78 & 0.000 \\
\hline
\end{tabular}



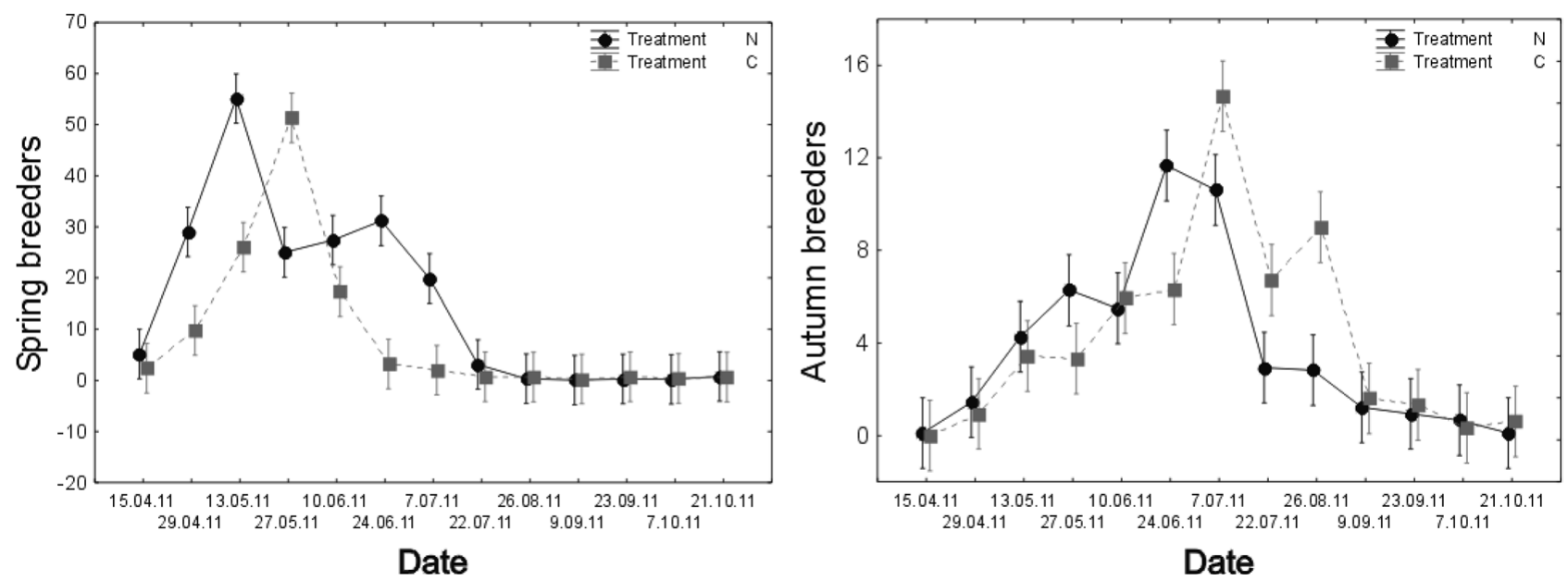

Fig. 4. Average abundance of spring and autumn breeding carabids recorded during the course of a year in wheat fields in which the soil was cultivated in one of two different ways: $\mathrm{N}$ - non-inversion, $\mathrm{C}$ - conventional. (The vertical lines indicate 0.95 confidence interval.)

type of soil cultivation. There were no significant differences between the two soil tillage methods in terms of the numbers of large and small zoophages (Table 3). Hemizoophagous beetles responded strongly to type of soil cultivation (Fig. 3) and were less abundant in conventionally cultivated than in reduced soil cultivated fields, especially in summer, when the maximum activity of Harpalus rufipes occurred. In the case of zoophagous carabids the response depended on the size of the beetles. Medium sized zoophagous organisms showed the strongest reaction (Fig. 3) with the peak in abundance occurring about 1 month later in the conventionally cultivated fields. After a late spring peak in abundance their numbers declined rapidly. The abundance of small zoophagous did not differ significantly in the two types of cultivation, except in autumn when the peak was significantly higher in conventionally cultivated fields. The largest fluctuations in abundance in time were recorded for large zoophagous species (Fig. 3). Average abundance of this group of carabids was similar in both types of soil cultivation.

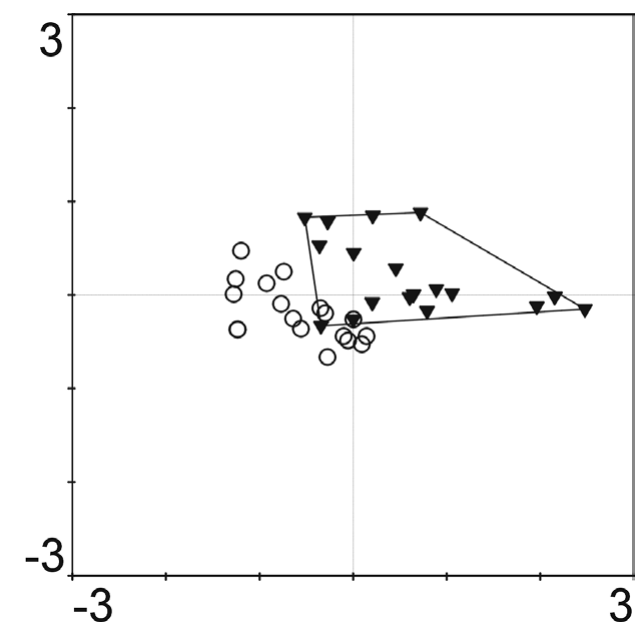

Fig. 5. Diagram of non-metric multidimensional scaling (NMDS) performed on Bray-Curtis similarity matrix of ground beetle assemblages, $\boldsymbol{\nabla}$ - assemblages of non-inversion tillage, $\bigcirc-$ assemblages of conventional tillage.

Analysis of the presence of spring and autumn breeding carabids using GLM indicates that treatment did not significantly affect the presence of autumn breeding species (Table 4). However, the occurrence in time of both of these group of beetles was significantly affected. Spring breeding carabids were strongly affected by the type of soil cultivation (Fig. 4), in that they were active earlier in the fields that were not ploughed and remained active to the end of summer. Peaks in activity were recorded in both summer and spring. In the conventionally cultivated fields the peak in activity of spring breeding carabids occurred a month later and then decreased faster than was recorded in non-conventionally cultivated fields. Autumn breeders exhibited a weaker reaction to type of cultivation, but their peak activity occurred significantly later in the conventionally cultivated fields.

The PERMANOVA (NPMANOVA) test revealed significant differences in the species compositions of the carabid assemblages in the two types of triticale cultivation $(\mathrm{F}=14.07, \mathrm{p}<0.001)$. The differences are revealed by the NMDS ordination of the carabid species composition (Fig. 5). The final two-dimensional solution of the NMDS ordination represented a total of $91 \%$ of the total variation of the original space (axis1: 19.7\%; axis 2: $9.5 \%$ ) at a final stress of 9.53 (Monte Carlo test, $\mathrm{P}=0.0001$ ).

\section{DISCUSSION}

The way soil is cultivated is an important factor determining its physical, chemical and biological properties, which can influence animal life such as carabids (Kladivco, 2001). Conventional soil tillage by slice furrow inversion with ploughs can destroy soil wildlife, either directly by killing it, or indirectly, by modifying the habitat and altering the availability of food (Kromp, 1999; Holland \& Luff, 2000; Holland, 2004). This study confirms the above as there were significantly fewer carabid beetles in fields tilled conventionally. Conservation tillage systems, which employ fewer machines and farming tools than conventional systems, have less effect on the structure of the soil 
and therefore on the abundance and demography of soil organisms (Kromp, 1999; Twardowski, 2010). However, the effect soil treatments have on arthropods, including carabid beetles, is equivocal. Most studies report an increase in abundance and species diversity of carabids with decrease in the intensity of mechanical disturbance (Luff, 1987; Stinner \& House, 1990; Brust, 1994; Digweed et al., 1995; Heimbach \& Garbe, 1995; Kroos \& Schaefer, 1998; Kromp, 1999; Brevault et al., 2007; Twardowski, 2010). Previous researchers have indicated that disrupting the structure of soil has an adverse effect on soil inhabiting invertebrate larvae and therefore the population of adult insects. Some authors claim that moving soil by ploughing positively promotes carabid mobility and activity, which results in an increase of their abundance (Barney \& Pass, 1986). Some studies (Tyler \& Ellis, 1979; Huusela-Vesitola, 1996; Hance, 2002; Andersen, 2003) indicate no significant influence of the type of soil cultivation on the abundance and species richness of carabids. Similarly, type of soil tillage had no significant effect on species richness in our experiment. Weibull et al. (2003) also report that farming practice is relatively less important than other landscape features, like heterogeneity, field margins, cropping system and weed cover.

Farming operations that disrupt the soil can affect the abundance, species richness and some life history traits of soil-dwelling beetles. That there are specific life history traits associated with particular agronomic practices is becoming more evident for a variety of traits and taxa (Wamser et al., 2012). Purtauf et al. (2005) and Schweiger et al. (2005) report that the different trophic groups of carabids respond differently to land management and landscape structure. Similarly, previous research indicates that hemizoophagous beetles are less vulnerable to habitat simplification then carnivorous species. In this study, we recorded that the temporal activity of hemizoophagous species was similar in both types of soil treatment. In conventional tillage, however, the numbers recorded was much greater during certain periods of the year. This may have resulted from increases in the food supply, in the form of plant pests, for this group of carabids. Andersen (1999) reports that the number caught in plots subject to reduced tillage were lower than in ploughed fields, probably because of the higher incidence there of pests. The sensitivity of zoophagous species to disturbance in agricultural habitats is a complex issue and depends on the size of the beetles. Large carabids are more vulnerable to environmental disturbance and more commonly occur in stable habitats with optimal environmental conditions. Larval, and pupal stages of large species are more likely to be damaged by farming processes, including ploughing (Kladivko, 2001; Hatten et al., 2007). Small zoophagous insects, most of which are macropteric, are characteristically more mobile during agrotechnical processes. Many Bembidion and Trechus spp. inhabit disturbed areas. Their dispersal ability may enable them to survive by quickly leaving ploughed fields (Luff \& Sanderson, 1992).
The activity of zoophagous beetles depends on the availability of food. When disturbance limits the availability of food, which favours large species of carabid, then more sensitive species are eliminated (Skalski et al., 2011; Eyre et al., 2013). When small species of carabid do not have to compete for food it can be said they inhabit a very favourable breeding environment. For example, Trechus quadristriatus survives and is not physically injured by soil tillage and becomes just as active again within a week or two (Purvis \& Bannon, 1992; Purvis \& Fadl, 2002). Ribera et al. (2001) also show that big species of carabids prefer undisturbed sites, whereas many small species, i.e. Bembidion, thrive in highly disturbed sites. However Baguette et al. (1997) and Holland \& Reynolds (2003) record high numbers of both small and large species at unploughed sites. They suggest that size is not important in determining their surviving soil cultivation. In the current study, only small zoophages did not react to the type of soil tillage.

Disrupting the structure of soil can affect the breeding cycle of carabid beetles. Skalski et al. (2010) suggest that spring breeders are more resistant to disturbance as they have relatively short larval stages and long adult life span. However, spring breeders reacted very strongly to ploughing in this study. Under conventional soil tillage they became active later and for a shorter period than under reduced tillage. One reason could be the availability of food. In conventionally tilled fields, where there were probably fewer pests, females were short of food and therefore oviposited later. The period of larval activity was also shorter. Contrary results are reported by Hatten et al. (2007), who conclude that the activity of spring breeders is greater in conventionally tilled fields. Autumn breeders were not significantly affected by the soil tillage system, although the analysis of the seasonal dynamics of their activity, indicates the level of activity late in the season was negatively affected by ploughing. This was counteracted by individuals being active for longer and a greater abundance of beetles in summer. Some authors claim that autumn species are highly sensitive to tillage and other agricultural practices (Skuhravý, 1958; Cárcamo et al., 1995). Autumn-breeders, whose larvae and pupae remain in the soil for a long time, are less likely to avoid the direct consequences of tillage (Ribera et al., 2001; Purvis \& Fadl, 2002; Twardowski, 2010).

Non-metric multidimensional scaling analysis and IndVal values confirm that the species composition of carabid beetle assemblages differed, with different assemblages in the different soil tillage systems studied.

\section{CONCLUSIONS}

The type of soil tillage had a considerable effect on Carabidae. The modification of the soil environment due to ploughing resulted in a decrease in the abundance of carabid beetles. The use of non-inversion tillage resulted in an increase in the activity of the biggest zoophages and the earlier appearance of both spring and autumn breeders.

ACKNOWLEDGEMENTS. We thank K. Russel for improving the English of this manuscript. 


\section{REFERENCES}

Aleksandrowicz O., Pakula B. \& Mazur J. 2008: Carabid beetles (Coleoptera: Carabidae) in the wheat field near Lębork. Stupskie Prace Biol. 5: 15-25 [in Polish, English abstr.].

ANDERSEN A. 1999: Plant protection in spring cereal production with reduced tillage. II. Pests and beneficials insects. - Crop Prot. 18: 651-657.

ANDERSEN A. 2003: Long-term experiments with reduced tillage in spring cereals. II. Effects on pest and beneficial insects. Crop Prot. 2: 147-152.

ANDERSON M.J. 2001: A new method for non-parametric multivariate analysis of variance. - Austral Ecol. 26: 32-46.

Arshad M.A. 1999: Tillage and soil quality. Tillage practices for sustainable agriculture and environmental quality in different agroecosystems. - Soil Till. Res. 53: 1-2.

Baguette M. \& Hance T. 1997: Carabid beetles and agricultural practices: influence of soil ploughing. - Biol. Agric. Hortic. 15: $185-190$

BARNey R.J. \& PASs B.C. 1986: Ground beetle (Coleoptera: Carabidae) populations in Kentucky alfalfa and influence of tillage. - J. Econ. Entomol. 79: 511-517.

Breavult T., Bikay S., Maldès J.M. \& Naudin K. 2007: Impact of a no-till mulch soil macrofauna communities in a cotton cropping system. — Soil Till. Res. 97: 140-149.

BRUST G.E. 1994: Natural enemies in straw-mulch reduce Colorado potato beetle populations and damage in potatoes. - Biol. Contr. 4: 163-169.

CÁrcamo H.A., Niemelä J. \& Spence J.R. 1995: Farming and ground beetles: effects of agronomic practice on populations and community structure. - Can. Entomol. 127: 123-140.

Digweed S.C., Currie C.R., Carcamo H.A. \& Spence J.R. 1995: Digging out the 'digging in effect' of pitfall traps: Influences of depletion and disturbance on catches of ground beetles (Coleoptera: Carabidae). - Pedobiologia 39: 561-576.

Eyre M.D., Luff M.L. \& Leifert C. 2013: Crop, field boundary, productivity and disturbance influences on ground beetles (Coleoptera, Carabidae) in the agroecosystem. - Agr. Ecosyst. Environ. 165: 60-67.

HANCE T. 2002: Impact of cultivation and crop husbandry practices. In: The Agroecology of Carabid Beetles. Intercept, Andover, pp. 231-249.

Hatten T.D., Bosque-Pérez N.A, Labonte J.R., Guy S.O. \& EIGENBRODE S.D. 2007: Effects of tillage on the activity density and biological diversity of carabid beetles in spring and winter crops. - Environ. Entomol. 36: 356-368.

Heimbach U. \& Garbe V. 1995: Effects of reduced tillage systems in sugar beet on predatory and pest arthropods. - Acta Jutl. 71: $195-208$

Hengeveld R. 1980: Polyphagy, oligophagy and food specialization in ground beetles (Coleoptera, Carabidae). - Neth. J. Zool. 30: 564-584.

Holland J.M. \& LufF M.L. 2000: The effects of agricultural practices on Carabidae in tem-perate agroecosystems. - Integr. Pest Manag. Rev. 5: 109-129.

Holland J.M. 2004: The environmental consequences of adopting conservation tillage in Europe: reviewing the evidence. Agr. Ecosyst. Environ. 103: 1-25.

Holland J.M. \& ReYnolds C.R. 2003: The impact of soil cultivation on arthropod (Coleoptera and Araneae) emergence on arable land. - Pedobiologia 47: 181-191.

HureJ M. \& Twardowski J.P. 2006: The influence of yellow lupin intercropped with spring triticale on predatory carabid beetles (Coleoptera: Carabidae). — Eur. J. Entomol. 103: 259-261.
HuRuk S. 2002: Carabids (Coleoptera, Carabidae) in strawberry plantations on brown soils. - Baltic J. Coleopterol. 2: 105116.

Huusela-Vesitola E. 1996: Effects of pesticide use and cultivation techniques on ground beetles (Col., Carabidae) in cereal fields. - Ann. Zool. Fenn. 33: 197-205.

IRMLER U. 2003: The spatial and temporal pattern of carabid beetles on arable fields in northern Germany (Schleswig-Holstein) and their value as ecological indicators. - Agr. Ecosyst. Environ. 98: 141-151.

Kladivko E.J. 2001: Tillage systems and soil ecology. - Soil Till. Res. 61: 61-76.

Korvula M.J. 2011: Useful model organisms, indicators, or both? Ground beetles (Coleoptera, Carabidae) reflecting environmental conditions. - ZooKeys 100: 287-317.

KROMP B. 1999: Carabid beetles in sustainable agriculture: a review of pest control efficacy, cultivation impact and enhancement. - Agr. Ecosyst. Environ. 74: 187-228.

Krooss S. \& Schaefer M. 1998: The effect of different farming systems on epigeic arthropods: a five-year study on the rove beetle fauna (Coleoptera: Staphylinidae) of winter wheat. Agr. Ecosyst. Environ. 69: 121-133.

LARSSON S.G. 1939: Entwicklungstypen und Entwicklungszeiten der dän Carabiden. - Entomol. Meddel. 20: 270-560.

Lövei G.L. \& Sunderland K.D. 1996: Ecology and behavior of ground beetles (Coleoptera: Carabidae). - Annu. Rev. Entomol. 41: 231-256.

LuFF M.L. 1987: Biology of polyphagous ground beetles in agriculture. - Agric. Zool. Rev. 2: 237-278.

LufF M.L. \& SANDERSON R.A. 1992: Analysis of Data on Cereal Invertebrates. MAFF Report, London, $39 \mathrm{pp}$.

Marasas M.E., SARANDOn S.J. \& Cicchino A.C. 2001: Changes in arthropod functional group in wheat crop under conventional and no tillage systems in Argentina. - Appl. Soil Ecol. 18: $61-68$.

Morris N.L., Miller P.C.H., Orson J.H. \& Froud-Williams R.J. 2010: The adoption of non-inversion tillage systems in the United Kingdom and the agronomic impact on soil, crops and the environment - A review. - Soil Till. Res. 108: 1-15.

Nietupski M., Sowiński P., SĄDej W. \& Kosewska A. 2010: Content of organic $\mathrm{C}$ and $\mathrm{pH}$ of bog and post-bog soils versus the presence of ground beetles Carabidae in Stary Dwór near Olsztyn. - J. Elementol. 15: 581-591.

Purtauf T., Dauber J. \& Wolters V. 2005: The response of carabids to landscape simplification differs between trophic groups. - Oecologia 142: 458-464.

Purvis G. \& BanNon J.W. 1992: Non-target effects of repeated methiocarb slug pellet application on carabid beetle (Coleoptera: Carabidae) activity in winter-sown cereals. - Ann. Appl. Biol. 121: 401-422.

PuRvis G. \& FADL A. 2002: The influence of cropping rotations and soil cultivation practice on the population ecology of carabids (Coleoptera: Carabidae) in arable land. - Pedobiologia 46: $452-474$.

Rainio J. \& Niemela J. 2003: Ground beetles (Coleoptera: Carabidae) as bioindicators. - Biodivers. Conserv. 12: 487-506.

Ribera I., Doledec S., Downie I.S. \& Foster G.N. 2001: Effect of land disturbance and stress on species traits of ground beetle assemblages. - Ecology 82: 1112-1129.

Sądej W., Kosewska A., SĄDej W. \& Nietupski M. 2012: Effects of fertilizer and land-use type on soil properties and ground beetle communities. - Bull. Insectol. 65: 239-246.

SASKA P. 2007: Diversity of carabids (Coleoptera: Carabidae) within two Dutch cereal fields and their boundaries. - Baltic J. Coleopterol. 7: 37-50. 
Schweiger O., Maelfait J.P., Van Wingerden W., Hendrick F., Billeter R., Speelmans M., Augenstein I., Aukema B., Aviron S., Bailey D., Bukacek R., Burel F., Diekotter T., Dirkse J., Frenzel M., Herzog F., Litra J., Roubalova M. \& Bugter R. 2005: Quantifying the impact of environmental factors on arthropod communities in agricultural landscapes across organizational levels and spatial scales. - J. Appl. Ecol. 42: $1129-1139$

Schwerk A. \& Szyszko J. 2011: Model of succession in degraded areas based on carabid beetles (Coleoptera, Carabidae). ZooKeys 100: 319-332.

Skalski T., Stone D., Kramarz P. \& Laskowski R. 2010: Ground beetle community responses to heavy metal contamination. Baltic J. Coleopterol. 10: 1-12.

Skalski T., KęDzior R., Maciejowski W. \& Kasprzak A. 2011: Soil and habitat preferences of ground beetles (Coleoptera, Carabidae) in natural mountain landscape. - Baltic J. Coleopterol. 11: 105-115.

SkŁodowski J.J. 2014: Effects of top-soil preparation and broadleaved tree mixture on carabid beetles in afforested fallow plots. - Restor. Ecol. 22: 13-21.

SKUHRAVÝ V. 1958: Einfluß landwirtschlaftlicher Maßnahmen auf die phänologie der feldcarabiden. - Folia Zool. 7: 325-338.

Šmilauer P. 2002: WinKyst 1.0. Ceske Budejovice, Czech Republic.
StinNer B.R. \& House G.J. 1990: Arthropods and other invertebrates in conservation-tillage agriculture. - Annu. Rev. Entomol. 35: 299-318.

SunderLAND K.D. 2002: Invertebrate pest control by carabids. In Holland J.M. (ed.): The Agroecology of Carabid Beetles. Intercept, Andover, pp. 165-214.

Thiele H.U. 1977: Carabid Beetles and their Environments. Springer, Berlin, 369 pp.

Twardowski J.P. 2010: The Effect of Reduced Tillage Systems in Winter Wheat Crop on the Assemblages of Epigeal and Soil Arthropods. Treatises and Monographs, UWP, Wrocław, 141 pp. [in Polish, English abstr.].

Tyler B.M.J. \& Ellis C.R. 1979: Ground beetle in three tillage plots in Ontario and observations on their importance as predators of the northern corn rootworm, Diabrotica longicornis (Coleoptera: Chrysomelidae). Proc. Entomol. Soc. Ont. 110: 65-73.

Wamser S., Diekötter T., Boldt L., Wolters V. \& Dauber J. 2012: Trait-specific effects of habitat isolation on carabid species richness and community composition in managed grasslands. - Insect Conserv. Divers. 5: 9-18.

Weibull A.C., Östman O. \& Granqvist A. 2003: Species richness in agroecosystems: the effect of landscape, habitat and farm management. — Biodivers. Conserv. 12: 1335-1355.

Received December 31, 2013; revised and accepted May 23, 2014 Prepublished online September 10, 2014 